\title{
THE UNIVERsity ofyork
}

Discussion Papers in Economics

\author{
No. $2003 / 14$ \\ An Asset Market Integration Test Based on \\ Observable Macroeconomic Stochastic Discount Factors \\ by \\ Peter N Smith, S Sorensen and M R Wickens
}

Department of Economics and Related Studies University of York Heslington

York, YO10 5DD 


\title{
An Asset Market Integration Test Based on Observable Macroeconomic Stochastic Discount Factors
}

\author{
P.N. Smith, S. Sorensen and M.R. Wickens ${ }^{1}$ \\ University of York \\ August 2003
}

\begin{abstract}
There are a number of tests and measures of the degree of integration in the literature. An example is the idea that integrated markets should provide rates of return that are highly correlated with one another and that a measure of correlation provides an appropriate test. This particular idea is clearly false; for substantial periods of time we don't ever see stocks traded on the same market moving together. Specific models of what prices risk in individual markets could provide the basis of a test of integration. However, as has been widely shown, any differences between these pricing models will be subject to arbitrage by informed traders and so cannot form the basis for a test.

In this paper we exploit the absence of arbitrage possibilities and the operation of the 'Law of One Price' in stochastic discount factor (SDF) theory to construct a test of integration based on a common approach to pricing assets in all markets, not only for stocks. The SDF approach that we adopt says that one SDF should price all assets as the model is not market or asset-specific.Unlike much of the literature, we adopt a direct parametric approach which takes estimates of an identical SDF from two asset markets and asks whether the price of risk associated with this SDF is the same for the two assets as SDF theory says it should. Another distinctive feature of our approach is that we employ observable macroeconomic factors. This allows us to estimate and compare the estimated risk premia in the markets concerned, with and without the integration restriction being applied. The paper uses this methodology to test market integration between the UK equity and FOREX markets.

Our test rejects market integration for the consumption-based capital asset pricing model (CCAPM) and two variable SDF models based on consumption growth and inflation and on output and money growth. As equity and FOREX returns have a similar degree of variability, the finding that the risk premium in the FOREX market is generally much more variable than that in the equity market may contribute to the the test outcome.

\footnotetext{
${ }^{1}$ We are grateful to the ESRC for providing financial support for this research in grant No. L13830100140. The first author is grateful for the hospitality of the Economics Program, RSSS, Australian National University over the period during which this paper was written.

JEL classification: G12, C32. C51, E44
} 


\section{Introduction}

There are a number of tests and measures of the degree of financial market integration in the literature. An example is be the idea that integrated markets should provide rates of return that are highly correlated with one another and that a measure of correlation provides an appropriate test. This particular idea is clearly false; for substantial periods of time we don't even see stocks that are traded on the same market moving together. Specific models of what prices risk in individual markets could provide the basis of a test of integration. However, as has been widely shown, any differences between these pricing models will be subject to arbitrage by informed traders and so cannot form the basis for a test. Adam et al. (2002) provide a recent survey of tests of integration between various stock markets.

In this paper we exploit the absence of arbitrage possibilities and the operation of the 'Law of One Price' in stochastic discount factor (SDF) theory to construct a test of integration based on a common approach to pricing assets in all markets, not only for stocks. The SDF approach that we adopt says that one SDF should price all assets - the model is not market or asset-specific.Unlike much of the literature, we adopt a direct parametric approach which takes estimates of an identical SDF from two asset markets and asks whether the price of risk associated with this SDF is the same for the two assets as SDF theory says it should. Another distinctive feature of our approach is that we employ observable macroeconomic factors. This allows us to estimate and compare the estimated risk premia in the markets concerned, with and without the integration restriction being applied. ${ }^{2}$

The paper uses this methodology to test market integration between the UK equity and FOREX markets. This approach tests a joint hypothesis of the integration of the two markets and the specification of the SDF. Hence, to mitigate the potential corruption of the test of integration by mispecification of the SDF, we exploit the extensive analysis in two previous papers on the two individual markets of the specification of the SDF (see Wickens and Smith (2001) and Smith, Sorensen and Wickens (2003)). Potentially, there are a large number of consumption-based models, as well as broader SDF models, that could be analysed in the environment that is proposed in this paper. The results from previous work suggest, however, that this number can be reduced substantially. In a study of the US and UK equity risk premia, Smith, Sorenson and Wickens (2003) find that the simple positive relationship between the level of the excess return and the variance implied by the static CAPM is not supported by the evidence. Nor is there much evidence in favour of the CCAPM with power utility, or of generalisations to allow for time-non-separable

\footnotetext{
2 The widely used unobserved factor approach is discussed in detail in Smith and Wickens (2002).
} 
preferences. Instead, two-variable SDF models that include a role for inflation in addition to consumption growth perform much better in terms of providing significantly priced sources of risk. There is, in addition, some evidence of alternative multiple-factor SDF models also providing priced factors. Similar results for the FOREX risk premium are fiound by Wickens and Smith (2001). Even allowing for different versions of the model that allow for complete and incomplete markets and take the perspectives of domestic US or UK investors, the evidence suggests that the CCAPM with power utility does not provide a good model of the FOREX risk premium. There is, however, some evidence in favour of two-factor SDF models of a similar type to those employed to model equity returns. In particular, evidence is found in favour of a two-factor model with money and output growth as factors.

In this paper we confine ourselves to analysing the two-factor SDF models for UK investors but we include the CCAPM for comparability. Given their importance in our previous work, we consider nominal sources of risk. It should be emphasised that all of the models we examine models impose the absence of arbitrage possibilities.

Our approach can be contrasted with that of Chen and Knez (1995). Following the work of Hansen and Jagannathan (1991), Chen and Knez reverse-engineer the set of possible SDFs that could generate observed asset returns and then compare these SDFs across assets. The extent to which they are different provides a test of market integration. Whilst this type of analysis can provide some tests of integration, it cannot provide a measure of the importance of different sources of risk in the markets concerned. By estimating the risk premia directly, our approach does provide such measures

In the next section we set out the SDF approach and the set of asset pricing equations that result. Subsequent development of the CCAPM and other SDF models produces the individual and joint models for asset returns that we estimate. These form the basis of the test for integration. Following description of the data, section 3 presents the estimation and testing results and measures of the risk premia. Our conclusions are presented in the final section.

\section{Theoretical models of the risk premium}

\subsection{The SDF model of asset pricing for asset returns}

The SDF model is based on the simple idea that $P_{t}$, the price of a one-period asset at the beginning of period $t$, is determined by the expected discounted value of its pay-off at the start of period $t+1$, namely, $X_{t+1}$ :

$$
P_{t}=E_{t}\left[M_{t+1} X_{t+1}\right]
$$


where $M_{t+1}$ is the stochastic discount factor, or pricing kernel (see Cochrane (2001) for a survey of SDF theory). For equity, the payoff is $X_{t+1}=P_{t+1}+D_{t+1}$, where $D_{t+1}$ are dividend payments assumed to be made at the start of period $t+1$. The pricing equation can also be written

$$
1=E_{t}\left[M_{t+1} \frac{X_{t+1}}{P_{t}}\right]=E_{t}\left[M_{t+1} R_{t+1}\right],
$$

where $R_{t+1}=1+r_{t+1}=X_{t+1} / P_{t}=\left(P_{t+1}+D_{t+1}\right) / P_{t}$ is the gross return and $r_{t+1}$ is the return. For FOREX the domestic investor can receive the risky return $R_{t+1}=S_{t+1}\left(1+i_{t+1}^{*}\right) / S_{t}$ from investing in one unit of the overseas asset. This has the risk-free component $i_{t+1}^{*}$ denominated in foreign currency and the risky component resulting from the change in the exchange rate $S_{t+1} / S_{t}$. $i_{t+1}^{*}$ is the nominal interest rate and the exchange rate $S_{t}$ is defined as the price of foreign currency. The pricing equation (1 or 2 ) has an identical form for all assets.

For any return $R_{t+1}$ taking logarithms and assuming log-normality - and noting that if $\ln x$ is $N\left(\mu, \sigma^{2}\right)$ then $\ln E(x)=\mu+\frac{\sigma^{2}}{2}$ - we obtain

$$
\begin{aligned}
0 & =\ln E_{t}\left[M_{t+1} R_{t+1}\right] \\
& =E_{t}\left[\ln \left(M_{t+1} R_{t+1}\right)\right]+V_{t}\left[\ln \left(M_{t+1} R_{t+1}\right)\right] / 2 \\
& =E_{t}\left(m_{t+1}\right)+E_{t}\left(r_{t+1}\right)+V_{t}\left(m_{t+1}\right) / 2+V_{t}\left(r_{t+1}\right) / 2+\operatorname{cov}_{t}\left(m_{t+1}, r_{t+1}\right)
\end{aligned}
$$

where $m_{t+1}=\ln M_{t+1}$. Hence the pricing equation can be written

$$
E_{t}\left(r_{t+1}\right)+E_{t}\left(m_{t+1}\right)+V_{t}\left(m_{t+1}\right) / 2+V_{t}\left(r_{t+1}\right) / 2=-\operatorname{cov}_{t}\left(m_{t+1}, r_{t+1}\right)
$$

If the asset is risk-free then its return is known at the start of period $t$ implying $r_{t+1} \equiv r_{t}^{f}$, $E_{t}\left(r_{t+1}\right)=r_{t}^{f}$ and $V_{t}\left(r_{t+1}\right)=0$. The pricing equation for the risk-free asset can therefore be written

$$
E_{t}\left(m_{t+1}\right)+r_{t}^{f}+\frac{1}{2} V_{t}\left(m_{t+1}\right)=0 .
$$

Subtracting the two pricing equations gives the expected excess return on the risky asset

$$
E_{t}\left(r_{t+1}-r_{t}^{f}\right)+\frac{1}{2} V_{t}\left(r_{t+1}\right)=-\operatorname{Cov}_{t}\left(m_{t+1}, r_{t+1}\right) .
$$

This is the key no-arbitrage condition that all correctly priced assets must satisfy when their returns are lognormally distributed. The right-hand side is the risk premium and $\frac{1}{2} V_{t}\left(r_{t+1}\right)$ is the Jensen effect. We note that $V_{t}\left(r_{t+1}\right)=V_{t}\left(r_{t+1}-r_{t}^{f}\right)$ and $\operatorname{Cov}_{t}\left(m_{t+1}, r_{t+1}\right)=\operatorname{Cov}_{t}\left(m_{t+1}, r_{t+1}-r_{t}^{f}\right)$ as $r_{t}^{f}$ is known at time $t$. 


\subsubsection{Real versus nominal returns}

The pricing equation (1) and the no-arbitrage condition (3) hold whether the variables, including the discount factor, are expressed in nominal or real terms. Although it is common to specify the discount factor in real terms, as a real risk-free rate does not exist in practice, we shall specify returns in nominal terms. Assuming no default risk, the nominal risk-free rate is a Treasury bill rate. We therefore need to re-express the no-arbitrage condition accordingly.

We assume that equations (1) and (3) are expressed in real terms with $M_{t+1}$ as the real ex-post discount factor and $r_{t+1}$ and $r_{t}^{f}$ as real ex-post rates of return. We now let $i_{t+1}$ and $i_{t}^{f}$ be the respective nominal rates of return and we let $P_{t}^{c}$ be the consumer price index at the start of period t. Equation (2) can therefore be written

$$
\begin{aligned}
1 & =E_{t}\left[M_{t+1} \cdot\left(1+r_{t+1}\right)\right] \\
& =E_{t}\left[M_{t+1} \cdot \frac{1+i_{t+1}}{1+\pi_{t+1}}\right] \\
& =E_{t}\left[\frac{M_{t+1}}{1+\pi_{t+1}} \cdot\left(1+i_{t+1}\right)\right]
\end{aligned}
$$

where $1+r_{t+1}=\frac{1+i_{t+1}}{1+\pi_{t+1}}$ and $1+\pi_{t+1}=\frac{P_{t+1}^{c}}{P_{t}^{c}}$. It can be shown that the no-arbitrage condition for nominal returns and a real discount factor is

$$
E_{t}\left(i_{t+1}-i_{t}^{f}\right)+\frac{1}{2} V_{t}\left(i_{t+1}\right)=-\operatorname{Cov}_{t}\left(m_{t+1}, i_{t+1}\right)+\operatorname{Cov}_{t}\left(\pi_{t+1}, i_{t+1}\right)
$$

Thus there is an extra term in the conditional covariance of inflation with the nominal (excess) return.

\subsection{Asset Market Integration}

The key feature of the SDF approach is that if markets are integrated, equation (4) applies to all assets - i.e. if the Law of One Price prevails and arbitrage drives risk-adjusted returns together. In the case of equity and FOREX their nominal returns should satisfy:

$$
\begin{aligned}
& E_{t}\left(i_{t+1}^{e}-i_{t}^{f}\right)+\frac{1}{2} V_{t}\left(i_{t+1}\right)=-\operatorname{Cov}_{t}\left(m_{t+1}, i_{t+1}^{e}\right)+\operatorname{Cov}_{t}\left(\pi_{t+1}, i_{t+1}\right) \\
& E_{t}\left(i_{t+1}^{f x}-i_{t}^{f}\right)+\frac{1}{2} V_{t}\left(i_{t+1}\right)=-\operatorname{Cov}_{t}\left(m_{t+1}, i_{t+1}^{f x}\right)+\operatorname{Cov}_{t}\left(\pi_{t+1}, i_{t+1}\right)
\end{aligned}
$$

where the nominal return on equity is $i_{t+1}^{e}$ and the nominal return on FOREX is $i_{t+1}^{f x}$. In order to create a test of integration we need to specify $m_{t+1}$. We consider two models of the real discount factor. 


\subsection{Consumption-based models: C-CAPM with power utility}

The canonical model of the discount factor is the consumption-based CAPM. We consider this for nominal asset returns. Asset prices derive their value from the expected consumption streams of investors who choose to

$$
\max _{C_{t}} \mathcal{U}_{t}=U\left(C_{t}\right)+\beta E_{t}\left(\mathcal{U}_{t+1}\right)
$$

subject to the nominal budget constraint

$$
P_{t}^{c} C_{t}+W_{t+1}=P_{t}^{c} Y_{t}+W_{t}\left(1+i_{t}\right)
$$

where $C_{t}$ is real consumption, $Y_{t}$ is real non-asset income and $W_{t}$ is nominal financial wealth at the start of period $t$. The solution is the Euler equation

$$
E_{t}\left[\frac{\beta U^{\prime}\left(C_{t+1}\right)}{U^{\prime}\left(C_{t}\right)} \frac{P_{t}^{c}}{P_{t+1}^{c}}\left(1+i_{t+1}\right)\right]=1 .
$$

which was first estimated by Hansen and Singleton (1983). This implies that the C-CAPM has implicitly defined the real SDF as

$$
M_{t+1}=\frac{\beta U^{\prime}\left(C_{t+1}\right)}{U^{\prime}\left(C_{t}\right)}
$$

For the power utility function $U=\frac{C_{t}^{1-\sigma}-1}{1-\sigma}$ with constant coefficient of relative risk aversion $\sigma$, the real discount factor, or marginal rate of substitution between periods $t$ and $t+1$, is

$$
M_{t+1}=\beta\left(\frac{C_{t+1}}{C_{t}}\right)^{-\sigma}
$$

Since real consumption is usually defined in ex-post terms, the discount factor will also be in real ex-post terms. Taking logarithms, and ignoring all constants, we obtain

$$
m_{t+1}=-\sigma \Delta c_{t+1}
$$

where $c_{t}=\ln C_{t}$. The no-arbitrage condition in real terms becomes

$$
E_{t}\left(r_{t+1}-r_{t}^{f}\right)+\frac{1}{2} V_{t}\left(r_{t+1}\right)=\sigma \operatorname{Cov}_{t}\left(\Delta c_{t+1}, r_{t+1}\right)
$$

The interpretation of the real equity risk premium is that investors lose utility today by not consuming. To compensate investors who defer the utility from an extra unit of consumption today they need additional marginal utility from future consumption. Because marginal utility declines as consumption increases, a higher level of consumption is needed in the future. The return on the investment must be large enough to generate the required consumption in the future. The greater the consumption needed, the larger the return must be, hence the risk premium is larger the greater the predicted covariance between consumption and returns. 
In nominal terms the no-arbitrage condition can be written

$$
E_{t}\left(i_{t+1}-i_{t}^{f}\right)+\frac{1}{2} V_{t}\left(i_{t+1}\right)=\sigma \operatorname{Cov}_{t}\left(\Delta c_{t+1}, i_{t+1}\right)+\operatorname{Cov}_{t}\left(\pi_{t+1}, i_{t+1}\right)
$$

Thus the nominal risk premium involves the nominal return and has a second covariance term associated with consumer price inflation. The greater the covariance between nominal returns and inflation, the larger the risk premium. We have argued that the larger the future consumption needed, the higher real returns must be. This is also true for nominal returns. The extra risk is that nominal returns will be larger solely due to inflation.

The power utility version of the CCAPM is a restricted version of more general representations of preferences. Campbell (2003), amongst others, argues for the time non-separable preferences originally proposed by Kreps and Porteus (1987) and implemented in CES form by Epstein and Zin (1989, 1990 and 1991). The results in Smith, Sorensen and Wickens (2003) provide a direct test of this specification of preferences in the context of the method employed in the current paper. These results demonstrate that this generalisation adds little to the explanation of the behaviour of equity returns as the extra parameters are not statistically significant. Here, therefore, we provide estimates based only on the CCAPM with power utility.

\subsection{CAPM and the monetary model}

In Wickens and Smith (2001) the CCAPM for FOREX risk is found to be dominated by an implementation of the one-period CAPM. In this paper we consider how well CAPM might do as a model of equity risk. The argument in Wickens and Smith is that in practice mean-variance analysis is often used to hedge FOREX risk. The key issue is then how to measure the uncertainty that arises from the future return to the portfolio. According to monetary models of the exchange rate, pure currency risk can be expected to be a function of domestic and foreign money supplies and output. Wickens and Smith find that for the UK domestic investor the behaviour of domestic money and output were the most important. Using the argument that the same SDF should be relevant for pricing all assets, we also consider the potential role for money and output to be the fundamental sources of risk for the equity market. An additional rationale for the choice of these two risk factors in the domestic equity market is the general equilibrium argument that money and output growth represent the fundamental sources of nominal and real activity.

One could view such models from a general SDF perspective. If $z_{i t}(i=1, \ldots, n)$ are $n$ factors which are jointly $\log$ normally distributed with equity returns then the discount factor can be written

$$
m_{t+1}=-\sum_{i=1}^{n} \beta_{i} z_{i, t+1}
$$


This implies the no-arbitrage condition

$$
\begin{aligned}
E_{t}\left(r_{t+1}-r_{t}^{f}\right)+\frac{1}{2} V_{t}\left(r_{t+1}\right) & =\sum_{i} \beta_{i} \operatorname{Cov}_{t}\left(z_{i, t+1}, r_{t+1}\right) \\
& =\sum_{i} \beta_{i} f_{i t},
\end{aligned}
$$

where the $f_{i t}$ are known as common factors.

In the absence of the sort of clear theoretical foundations provided by general equilibrium theories of asset pricing, the problem is to identify potential souces of risk to include in the SDF model. The latent factor literature simply assumes that unobserved processes can be specified for the factors. As noted above, general equilibrium models imply that investors are concerned with future consumption, and in particular, consumption next period. The main holders of equity are financial institutions, especially pension funds. They act on behalf of investors' consumption at a much more distant point in the future. In assessing risk, financial institutions focus largely on short-term performance, and on the value of the portfolio. This suggests that the market equity risk premium may be more influenced by short-term price risk than longer-term considerations of consumption. The sort of factors that are likely to affect the price of equity in the short term are associated with the business cycle and inflation. Output and money could be good measures of these sources of risk.

\subsection{Alternative Related Approaches}

Whilst our analysis of a market integration is made from the perspective of alternative versions of the SDF model, others have chosen to rely on a single representation of the SDF model without providing evidence of its adequacy. Flood and Rose (2003) present a panel-data test of the integration of US equity markets using the level of the Fama-French return factors: market return, HML and SMB. They assume that the conditional covariance between the SDF and the risky return is a linear function of the factors. The theory provides no restrictions on the parameters on the factors in these linear pricing equations; the coefficients on the factors are allowed to vary between assets. This is the only parameter that Flood and Rose can identify across assets is that on the risk-free rate, and so this forms the basis of their test of integration. Despite their success in relating the Fama French factors to returns, it would seem unlikely that such linear relations provide a proper basis for carrying out the test. According to SDF theory, risk premia are based on the conditional covariances between the underlying discount factor and the risky return, and not on the return itself. It is only in models such as the Vasicek latent affine factor model that the risk premium is a linear function of the return. Our approach, which is more general, by contrast works directly with such covariances (compare with equation (7)). Furthermore, given that that 
the Fama-French factors are all portfolio returns themselves, and so may be asset-specific, tests based on these 'mimicking portfolios' are essentially tests based on relationships between relative rates of return rather than tests based on fundamental sources of risk . It would seem unlikely therefore that the factors chosen by Flood and Rose would be suitable for testing, for example, the integration of equity and FOREX markets.

\section{The Econometric Framework}

\subsection{Multivariate conditional heteroskedasticity models}

We need to model the distribution of the excess return on equity jointly with the macroeconomic factors in such a way that the mean of the conditional distribution of the excess return in period $t+1$, given information available at time $t$, satisfies the no-arbitrage condition. The conditional mean of the excess return involves selected time-varying second moments of the joint distribution. We therefore require a specification of the joint distribution that admits a time-varying variancecovariance matrix. A convenient choice is the multi-variate GARCH-in-mean (MGM) model.

Let $\mathbf{x}_{t+1}=\left(i_{t+1}^{e}-i_{t}^{f}, i_{t+1}^{f x}-i_{t}^{f}, z_{1, t+1}, z_{2, t+1}, \ldots\right)^{\prime}$, where $z_{1, t+1}, z_{2, t+1}, \ldots$ include the macroeconomic variables that give rise to the factors in the SDF through their conditional covariances with the excess return. In principle, they may also include additional variables that are jointly distributed with these macroeconomic variables as this may improve the estimate of the joint distribution. The MGM model can then be written

$$
\mathbf{x}_{t+1}=\boldsymbol{\alpha}+\boldsymbol{\Gamma} \mathbf{x}_{t}+\boldsymbol{\Theta} \mathbf{g}_{t}+\varepsilon_{t+1}
$$

where

$$
\begin{gathered}
\varepsilon_{t+1} \mid I_{t} \sim D\left[0, \mathbf{H}_{t+1}\right] \\
\mathbf{g}_{t}=\operatorname{vech}\left\{\mathbf{H}_{t+1}\right\}
\end{gathered}
$$

The vech operator converts the lower triangle of a symmetric matrix into a vector. The distribution is the multivariate $t$-distribution. The first equation of the model is restricted to satisfy the noarbitrage condition. Thus, in general, the first two rows of $\boldsymbol{\Gamma}$ are zero and the first two rows of $\boldsymbol{\Theta}$ are $\left(-\frac{1}{2}, 0,-\beta_{11},-\beta_{12},-\beta_{13}, \ldots\right)$ and $\left(0,-\frac{1}{2},-\beta_{11},-\beta_{12},-\beta_{13}, \ldots\right)$.

It will be noted that the theory requires that the macroeconomic variables display conditional heteroskedasticity. This is not something traditionally assumed in macro-econometrics, but seems to be present in our data. Ideally, we would like to use high frequency data for asset returns, but very little macroeconomic data are published for frequencies higher than one month, and then 
only a few variables are available. Although more macroeconomic variables are published at lower frequencies, they tend not to display conditional heteroskedasticity.

Whilst the MGM model is convenient, it is not ideal. First, it is heavily parameterised which can create problems for the numerical convergence of the maximum likelihood due to the likelihood being surface being relatively flat, and hence uninformative. Second, asset returns tend to be excessively volatile. Assuming a non-normal distribution such as a $t$-distribution can sometimes help in this regard by dealing with thick tails. The main problem, however, is not thick tails, but a small number of extreme values. The coefficients of the variance process of the MGM model have a tendency to produce a near unstable variance process in their attempt to fit these extreme values. In principle, a stochastic volatility model, which includes an extra random term in the variance, could capture these extreme values. Unfortunately, as far as we are aware, no multivariate stochastic model with in mean effects in the conditional covariances has been proposed in the literature.

In view of the need to restrict the number of coefficients to estimate, a commonly used specification of $\mathbf{H}_{t+1}$ is the Constant Conditional Correlation model discussed in Ding and Engle (1994) where the dynamics of the conditional covariances are driven by individual GARCH processes for the variances of each variable. Given that the SDF approach focusses on the importance of the contribution of covariances, restricting their dynamics in this way, and not allowing the correlations to be time-varying, seems too restrictive. ${ }^{3}$

As a result, we specify $\mathbf{H}_{t+1}$ using the BEKK model originally proposed by Engle and Kroner (1995). This takes the form:

$$
\operatorname{vech}\left(\mathbf{H}_{t+1}\right)=\boldsymbol{\Lambda}+\sum_{i=0}^{p-1} \boldsymbol{\Phi}_{i} \operatorname{vech}\left(\mathbf{H}_{t-i}\right)+\Sigma_{j=0}^{q-1} \mathbf{\Theta}_{j} \operatorname{vech}\left(\varepsilon_{t-j} \varepsilon_{t-j}^{\prime}\right)
$$

where $\boldsymbol{\Lambda}, \boldsymbol{\Phi}$ and $\boldsymbol{\Theta}$ may be unrestricted. With $n-1$ factors $z_{i t}$ then $\boldsymbol{\Phi}$ and $\boldsymbol{\Theta}$ are both square matrices of size $n(n+1) / 2$ and $\boldsymbol{\Lambda}$ is a size $n(n+1) / 2$ vector. A formulation of this model which can make implementation easier is the error-correction formulation or VECM BEKK:

$$
\mathbf{H}_{t+1}=\mathbf{V}^{\prime} \mathbf{V}+\mathbf{A}^{\prime}\left(\mathbf{H}_{t}-\mathbf{V}^{\prime} \mathbf{V}\right) \mathbf{A}+\mathbf{B}^{\prime}\left(\varepsilon_{t} \varepsilon_{t}^{\prime}-\mathbf{V}^{\prime} \mathbf{V}\right) \mathbf{B}
$$

where the first term on the RHS is the long-run or unconditional covariance matrix. This can be initialised with starting values from sample averages. The remaining terms capture short-run deviations from this long run. A restricted version of this formulation is to specify $\mathbf{V}$ to be lower triangular, the ARCH matrix $\mathbf{B}$ to be fully parameterised to allow for full generality in

\footnotetext{
3 The attraction of the reduction in parameterisation offered by the CCC model has led to an extension to the dynamics in the DCC proposed recently by Engle( 2000).
} 
the transmission of shocks and the GARCH matrix $\mathbf{A}$ to be a symmetric matrices which reduces parameter numbers but allows for correlation over time in elements of the covariance system. A further restriction is that we require that the covariance function is stationary. This is satisfied if the absolute value of the eigenvalues of $(A \otimes A)+(B \otimes B)$ lie inside the unit circle where $\otimes$ is the Kronecker product.

We employ two alternative structures for the VECM BEKK model for the models that we estimate. In the first case we condition on consumption growth and inflation and in the second case on money and output growth Thus the vector $\mathbf{x}_{t+1}$ for the first models of the nominal equity and FOREX returns are $\mathbf{x}_{t+1}=\left(i_{t+1}^{e}-i_{t}^{f}, i_{t+1}^{f x}-i_{t}^{f}, \pi_{t+1}, \Delta c_{t+1}\right)^{\prime}$ whilst that for the second models is $\mathbf{x}_{t+1}=\left(i_{t+1}^{e}-i_{t}^{f}, i_{t+1}^{f x}-i_{t}^{f}, \Delta m_{t+1}, \Delta y_{t+1}\right)^{\prime}$. A first order vector autoregression for the macroeconomic variables is found to be sufficient to capture the serial dependence in their means, a $\operatorname{VECM~BEKK}(1,1)$ model is found to be adequate for the multivariate variance-covariance process.

For greater generality, instead of assuming that $\varepsilon_{t}$ has a multivariate Normal distribution, we assume that it has a multivariate $t$-distribution. This introduces a technical problem: unlike the Normal distribution, the moment generating function of the $t$-distribution does not exist and hence, strictly, the logarithm of the Euler equation does not exist.

\section{Results, Tests and Risk Premia}

\subsection{The Data}

The data are monthly (1975.6-2002.6). The equity returns are constructed from the MSCI total equity return index, the FOREX returns are formed from the spot exchange rate of Sterling relative to the US dollar and one-month Treasury Bill interest rates for the two countries. The Retail Price Index (RPI) is used to construct price inflation, M0 is the narrow definition money supply and output is measured by the volume index of industrial production all from Datastream. Total real non-durable consumption growth is especially provided by the NIESR. All data are expressed in equivalent annual percentages.

\subsection{Estimation Results and Integration Tests}

The estimation results for two versions of each of the three models outlined above are presented in Table 1. These are the CCAPM, the two factor SDF model with consumption growth and inflation as the two factors and a second two-factor SDF model with output growth and money growth as the two factors. In the first two models the restriction on the coefficient on the covariance of the risky return with inflation to -1 is applied. The estimate of the coefficient on the covariance with consumption growth is therefore an estimate of the coefficient of relative risk aversion. The 
coefficients are estimated with less precision than those presented in our earlier work reflecting the loss of degrees of freedom implied by a joint model of pricing equity and FOREX risk using the same sample size. Taking the first model where this estimate is allowed to differ between assets, we obtain estimates of the CRRA that are large and implausible from the perspective of the theory. The estimate for the equity market is somewhat larger than that for FOREX. The test of integration of the two markets for the CCAPM is a test, therefore, of whether these two coefficient estimates are the same. Estimates for the restricted model are presented as model 2. The value of the likelihood ratio test of integration is 15.78 which is significant at less than the $0.05 \%$ level given that the test is distributed $\chi^{2}(1)$ in this case.

The CCAPM is dominated by the two factor SDF models presented as models $3-6$. These are models where no restriction is applied on the coefficients on the two conditional covariances between the risky excess return and the macroeconomic factor. The likelihood ratio test for the CCAPM restriction between models 1 and 3 has a value of 16.04 which is also significant at less than the $0.05 \%$ level given that the test is distributed $\chi^{2}(2)$ in this case. In the equation for equity returns the coefficients on consumption growth and inflation reflect the estimates presented in Smith, Sorenson and Wickens (2003) in that the coefficient on the inflation covariance far exceeds that implied by the power-utility CCAPM in real terms. Likewise the coefficient on the consumption covariance is again much larger than would be regarded as a plausible measure of the degree of relative risk aversion implied by the CCAPM in real terms. The coefficents in the FOREX return equation are also representative of our earlier work reported in Wickens and Smith (2001). For the UK investor the coefficient on the consumption covariance is very large and positive as is that on the inflation covariance. It should be noted that the major disagreement on coefficient sign between the two parts of the model is on the inflation covariance. This is the main source of the rejection of market integration implied by the test statistic comparing model 3 with model 4 that imposes identical prices of risk in both markets. The LR test of integration has a value of 7.3 which is significant at the $2.5 \%$ level given that the statistic is distributed $\chi^{2}(2)$. This rejection is quite decisive given the relative imprecision of the coefficient estimates themselves.

The second set of estimates take output and money growth as the SDF. In model 5 the results for both excess returns in the model imply a positive relation with the covariance with money growth and negative with that with output growth. This model is found in Wickens and Smith (2001) to be the best description of the FOREX return - again in the current environment the coefficients are estimated with less precision. The integration test for this model has a value of 11.88 which is significant at the $0.25 \%$ level again providing a clear rejection of integration.

The estimation results also provide some comparative information about the nature of the 
risk premium in the two markets. For models apart from the CCAPM, we see that the risk premium on the FOREX market is smaller on average than that for equity at $2 \%$ or less rather than more than $8 \%$ for equity. This is also reflected in lower excess returns for FOREX than equity. Unconditional analysis might suggest therefore that the FOREX risk premium is less economically important. However, the FOREX risk premium has a larger variance, in some cases much larger. As a result, the proportion of the variance of the observed excess return explained by variation in the FOREX risk premium is greater than $15 \%$ compared with the less than $10 \%$ for the equity risk premium. This is given that the variability of the underlying returns series are similar in order of magnitude terms : the sample standard deviation of the FOREX return at 38.11 is, however, smaller than 54.01, that of the equity return. These results are further illuminated by examination of Figures 1 to 6 which show the estimated risk premia and the conditional covariances that they are constructed from. Figure 1 shows the equity return and the estimated risk premium from model 3. The estimated risk premium is predominantly positive although there are short periods, mainly in the 1970s when the risk premium is negative. These episodes appear to be when there are negative shocks to the covariance between the excess return to equity and consumption growth, see Figure 3. Figure 4 is the corresponding plot for inflation. The conditional covariance between excess equity returns and consumption are generally positive and that with inflation mainly negative. In order to produce a positive equity risk premium, the signs of the coefficients must reflect those of the conditional covariances. The covariances with the FOREX return are somewhat different to those for equity. Whilst they are not expected to be the same, the fact that the covariance with inflation in Figure 6 is predominantly positive explains the difference in the estimated price of risk which generates the rejection of market integration.

In the case of model 5; the output and money growth model, the risk premia are shown in Figures 7 and 8 . The variance of the equity risk premium in this model is much smaller than in model 3 reflecting lower prices of risk and lower variability in the conditional covariances. The risk premium in the FOREX market is, however, as variable as in the consumption growth and inflation model. This is due to the large positive price of risk associated with money growth. This feature which was also found to be of importance in the more general study of FOREX risk in Wickens and Smith (2001) contributes greatly to the rejection of market integration. 
Table 1. Estimates of various no-arbitrage equations for equity and forex returns

\begin{tabular}{|c|c|c|c|c|c|c|c|c|c|c|c|c|}
\hline \multirow{2}{*}{$\begin{array}{c}\text { Model } \\
\text { Dependent Variable }\end{array}$} & \multicolumn{2}{|c|}{1} & \multicolumn{2}{|c|}{2} & \multicolumn{2}{|c|}{3} & \multicolumn{2}{|c|}{4} & \multicolumn{2}{|c|}{5} & \multicolumn{2}{|c|}{6} \\
\hline & $i_{t+1}^{e}$ & $i_{t+1}^{f x}$ & $i_{t+1}^{e}$ & $i_{t+1}^{f x}$ & $i_{t+1}^{e}$ & $i_{t+1}^{f x}$ & $i_{t+1}^{e}$ & $i_{t+1}^{f x}$ & $i_{t+1}^{e}$ & $i_{t+1}^{f x}$ & $i_{t+1}^{e}$ & $i_{t+1}^{f x}$ \\
\hline$\overline{\mathrm{V}_{t}\left(i_{t+1}^{e}\right)}$ & -0.5 & & -0.5 & & -0.5 & & -0.5 & & -0.5 & & -0.5 & \\
\hline $\mathrm{V}_{t}\left(i_{t+1}^{f x}\right)$ & & -0.5 & & -0.5 & & -0.5 & & -0.5 & & -0.5 & & -0.5 \\
\hline $\mathrm{C}_{t}\left(\Delta c_{t+1}, i_{t+1}^{e}\right)$ & $\underset{(1.95)}{153.45}$ & & $\begin{array}{l}39.46 \\
(1.22)\end{array}$ & & $\begin{array}{c}244.18 \\
(1.30)\end{array}$ & & $\begin{array}{l}74.80 \\
(0.49)\end{array}$ & & & & & \\
\hline $\mathrm{C}_{t}\left(\Delta c_{t+1}, i_{t+1}^{f x}\right)$ & & $\begin{array}{l}69.93 \\
(1.21)\end{array}$ & & $\begin{array}{l}39.46 \\
(1.22)\end{array}$ & & $\begin{array}{c}151.55 \\
(1.36)\end{array}$ & & $\begin{array}{l}74.80 \\
(0.49)\end{array}$ & & & & \\
\hline $\mathrm{C}_{t}\left(\pi_{t+1}, i_{t+1}^{e}\right)$ & -1 & & -1 & & $-\underset{(1.89)}{1840.7}$ & & $\begin{array}{c}1824.6 \\
(3.76)\end{array}$ & & & & & \\
\hline $\mathrm{C}_{t}\left(\pi_{t+1}, i_{t+1}^{f x}\right)$ & & -1 & & -1 & & 1149.5 & & 1824.6 & & & & \\
\hline $\mathrm{C}_{t}\left(\Delta q_{t+1}, i_{t+1}^{e}\right)$ & & & & & & & & & $-\underset{(1.65)}{173.33}$ & & $\begin{array}{c}-97.04 \\
(1.16)\end{array}$ & \\
\hline $\mathrm{C}_{t}\left(\Delta q_{t+1}, i_{t+1}^{f x}\right)$ & & & & & & & & & & $-\underset{(1.07)}{121.32}$ & & $\begin{array}{c}-97.04 \\
(1.16)\end{array}$ \\
\hline $\mathrm{C}_{t}\left(\Delta m_{t+1}, i_{t+1}^{e}\right)$ & & & & & & & & & $\begin{array}{c}120.38 \\
(0.53)\end{array}$ & & 1003.50 & \\
\hline $\mathrm{C}_{t}\left(\Delta m_{t+1}, i_{t+1}^{f x}\right)$ & & & & & & & & & & $\begin{array}{c}1472.5 \\
(2.44)\end{array}$ & & $\begin{array}{c}1003.50 \\
(2.17)\end{array}$ \\
\hline Dummy, $d_{t}$ & $\begin{array}{c}-0.308 \\
(1.25)\end{array}$ & & $\begin{array}{c}-0.280 \\
(2.52)\end{array}$ & & $\begin{array}{c}-0.269 \\
(6.71)\end{array}$ & & $\begin{array}{c}-0.312 \\
(3.62) \\
\end{array}$ & & $\begin{array}{c}-0.343 \\
(5.89)\end{array}$ & & $\begin{array}{c}-0.338 \\
(3.05)\end{array}$ & \\
\hline Deg of Freedom & & & & & $\begin{array}{l}8.2 \\
(4 .\end{array}$ & & & & & & & \\
\hline Log-likelihood & & 3.53 & & .64 & 366 & & 366 & .90 & & .31 & & .37 \\
\hline $\begin{array}{c}\text { Mean risk premium } \\
\qquad\left|\lambda_{\max }\right|\end{array}$ & $5.36 \%$ & $\begin{array}{l}-0.852 \% \\
88\end{array}$ & $\begin{array}{r}1.56 \% \\
0\end{array}$ & $\begin{array}{l}-0.850 \% \\
84\end{array}$ & $\begin{array}{r}8.78 \% \\
0.9\end{array}$ & $2.96 \%$ & $\begin{array}{r}10.08 \% \\
0 .\end{array}$ & $\begin{array}{l}1.97 \% \\
79\end{array}$ & $\begin{array}{r}8.02 \% \\
0\end{array}$ & $-2.14 \%$ & $\begin{array}{r}10.56 \% \\
0\end{array}$ & $\begin{array}{l}-0.404 \% \\
90\end{array}$ \\
\hline $\bar{\varepsilon}_{t+1}$ & 3.16 & 1.02 & 6.90 & 0.983 & -0.524 & -2.89 & -1.51 & -1.89 & 0.526 & 2.14 & -2.02 & 0.455 \\
\hline $\mathrm{V}\left(\phi_{t+1}\right)$ & 39.69 & 10.61 & 8.60 & 5.03 & 253.52 & 286.89 & 90.16 & 239.2 & 43.05 & 246.24 & 42.29 & 158.71 \\
\hline$\frac{\mathrm{V}\left(\phi_{t+1}\right)}{\mathrm{V}\left(i_{t+1}^{j}+\frac{1}{2} \mathrm{~V}_{t}\left(i_{t+1}^{j}\right)-\widehat{\alpha} D\right)}$ & 0.0137 & 0.00732 & 0.00295 & 0.00346 & 0.0869 & 0.1975 & 0.0311 & 0.1651 & 0.0148 & 0.1699 & 0.0146 & 0.1095 \\
\hline
\end{tabular}




\section{Conclusions}

In this paper we present a test of asset market integration based upon a very general approach to asset pricing, the SDF approach. Our test is constructed from parametric estimation of three models of the SDF. We show that this approach allows us to examine the sources and prices of risk and therefore the likely sources of rejection of integration. This represents an improvement over exisiting, including recently proposed, tests. Most of these tests have been applied to various stock markets and some are not applicabale to non-equity markets. The application of the test in this paper is to the possible integration of the UK equity and FOREX markets. We find strong evidence against integration in the case of all three of the models we examine. Whilst the testing of asset market integration cannot be model free, we show that our result is robust in the face of all three alternative models. Further work will examine whether this result can be extended across further markets and across additional countries.

\section{References}

Adam, K., T. Jappelli, A. Menichini, M. Padula and M. Pagano (2002) Analyse, compare and apply alternative indicators and monitoring methodologies to measure the evolution of capital market integration in the European Union, mimeo, University of Salerno.

Campbell, J.Y. (2003) Consumption-based asset pricing, in Handbook of the Economics of Finance, eds G. Constantinides, M. Harris and R. Stulz, Elsevier.

Campbell, J.Y., A. Lo and A. MacKinlay (1997) The Econometrics of Financial Markets, Princeton University Press, Princeton, New Jersey.

Chen, Z. and P.J. Knez (1995) Measurement of market integration and arbitrage, Review of Financial Studies, 8-2, 287-325.

Ding, Z. and R.F. Engle (1994) Large scale conditional covariaqnce matrix modelling, estimation and testing, mimeo, University of California, San Diego.

Engel, R.F.. (2000) Dynamic conditional correlation - a simple class of multivariate GARCH model, mimeo University of California, San Diego.

Engle, R.F. and K.K.Kroner (1995) Multivariate simultaneous generalised GARCH, Econometric Theory, 11, 122-150. 
Epstein, L.G. and S.E. Zin (1989) Substitution, risk aversion and the temporal behaviour of consumption and asset returns: a theoretical framework, Econometrica, 57, 937-968.

Epstein, L.G. and S.E. Zin (1990) First order risk aversion and the equity premium puzzle, Journal of Monetary Economics, 26, 387-407.

Epstein, L.G. and S.E. Zin (1991) Substitution, risk aversion and the temporal behaviour of consumption and asset returns: an empirical investigation, Journal of Political Economy, 99, 263-286.

Flood, R.P. and A.K. Rose (2003) Financial integration:a new methodology and an illustration, National Bureau of Economic Research Working Paper No. 9880.

Hansen, L.P. and K. Singleton (1983) Stochastic consumption, risk aversion and the temporal behaviour of asset returns, Journal of Political Economy, 249-265.

Hansen, L.P. and R. Jagannathan (1991) Implications of security market data for models of dynamic economies, Journal of Political Economy, 99-2, 225-262.

Kreps, D and E. Porteus (1978) Temporal resolution of uncertainty and dynamic choice theory, Econometrica, 46, 185-200.

Smith, P.N., S. Sorensen and M.R. Wickens (2003) Macroeconomic sources of equity risk, mimeo University of York.

Smith, P.N. and M.R. Wickens (2002) Asset pricing with observable stochastic discount factors, Journal of Economic Surveys, 16,3,397-446.

Wickens, M.R. and P.N. Smith (2001) Macroeconomic sources of FOREX risk, mimeo University of York; http://www-users.york.ac.uk/ pns2/forex.pdf 


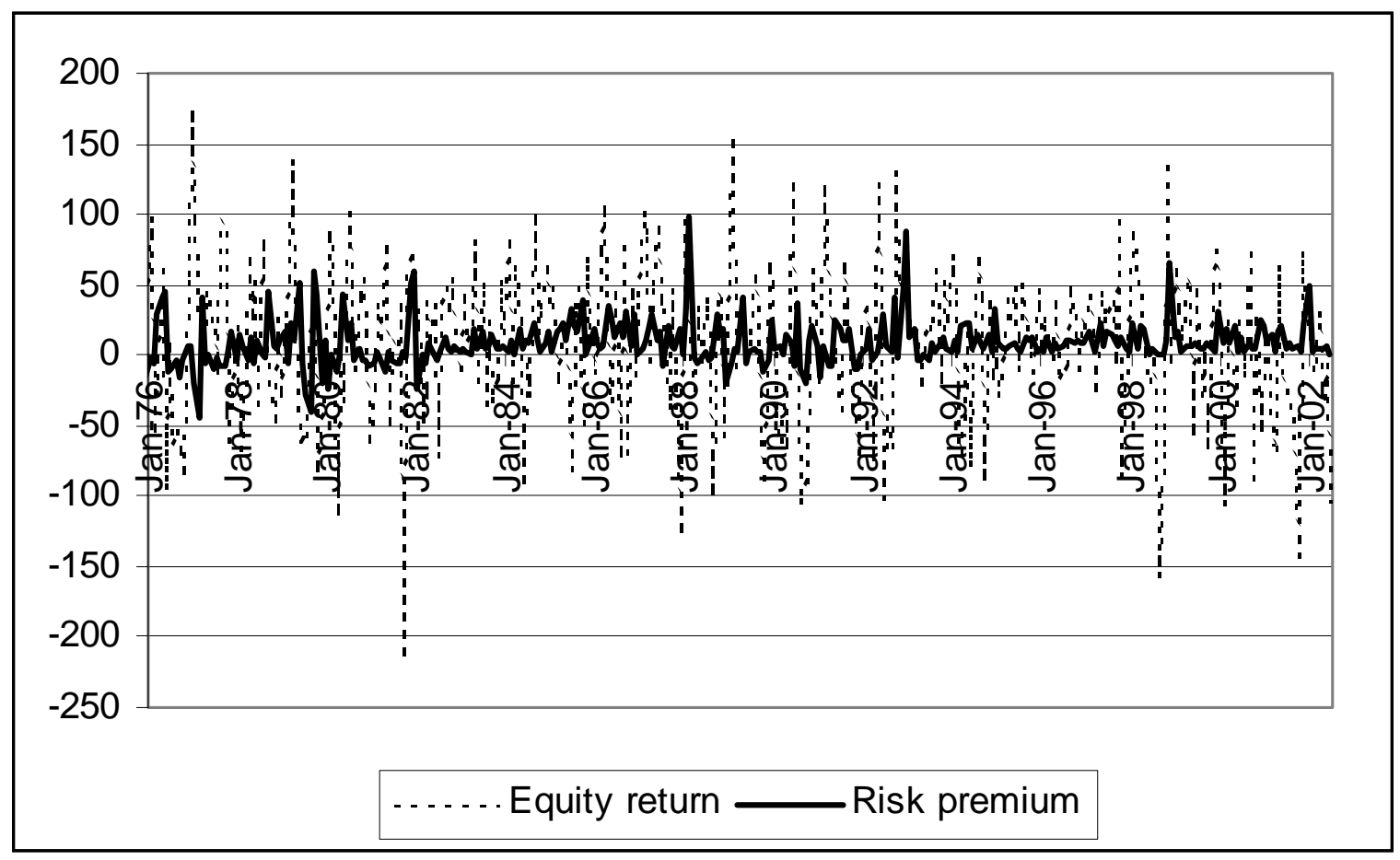

Figure 1: Equity return and risk premium for model 3 


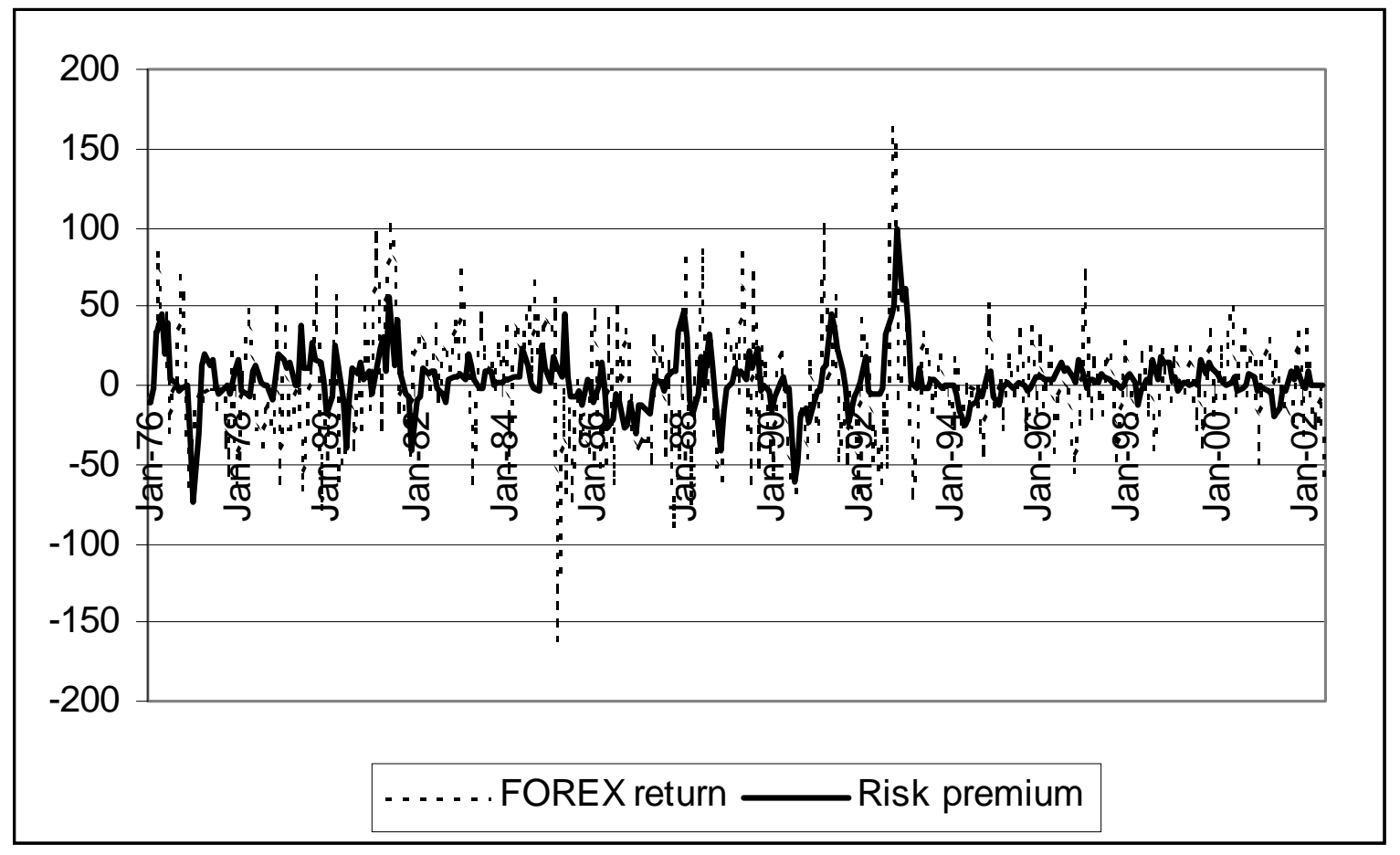

Figure 2: FOREX return and risk premium for model 3 


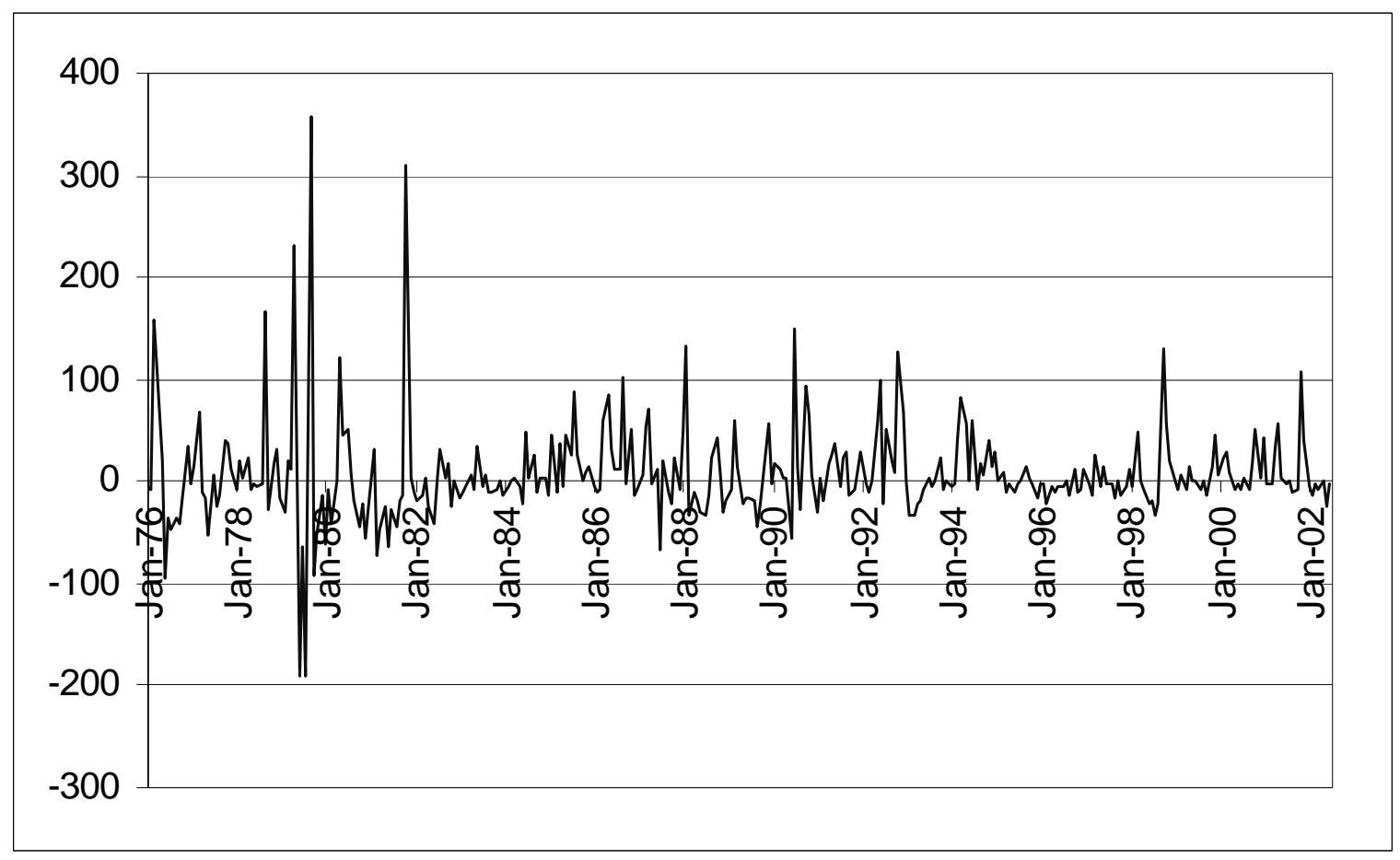

Figure 3: Conditional covariance between equity return and consumption growth 


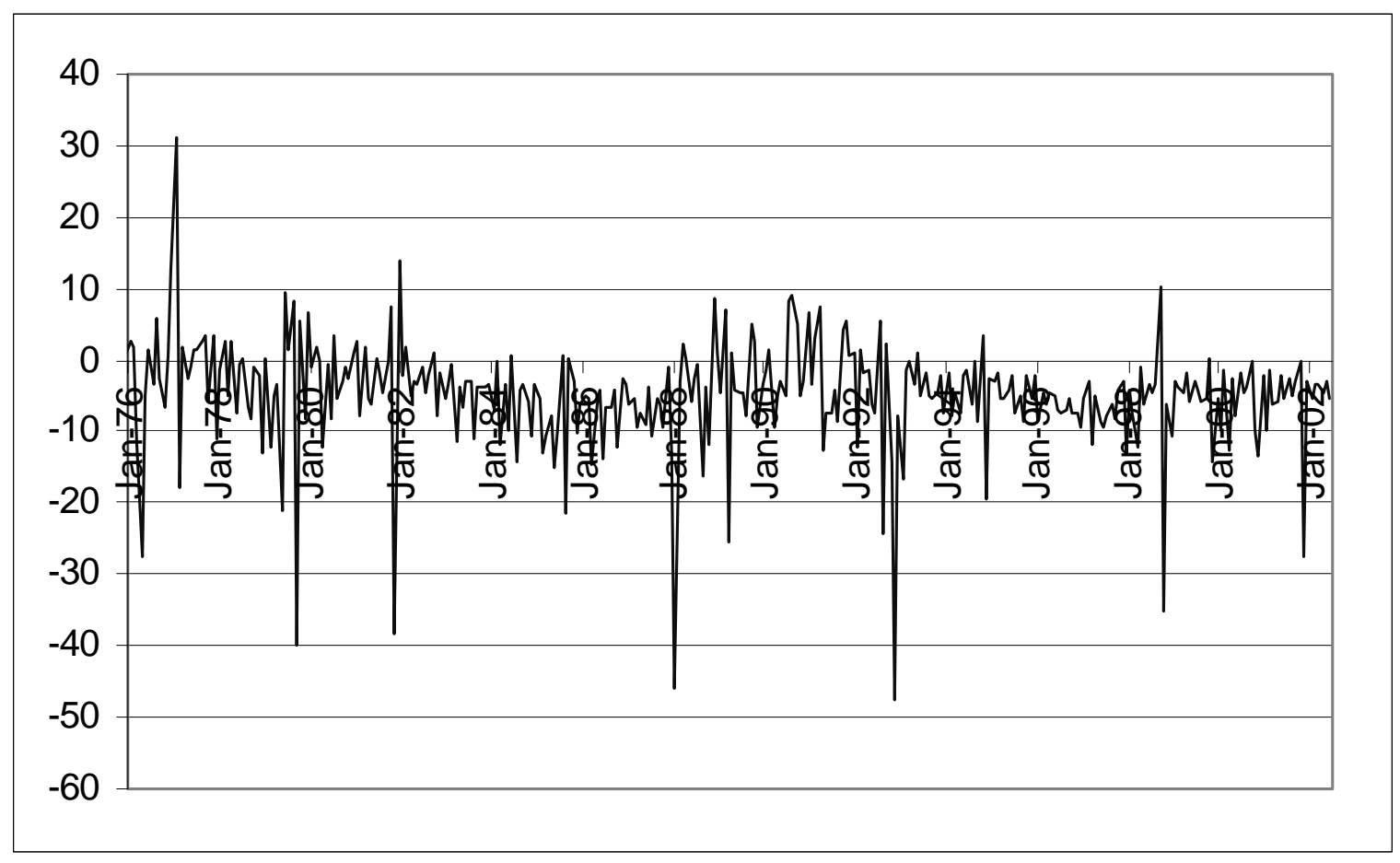

Figure 4: Conditional covariance between equity return and inflation 


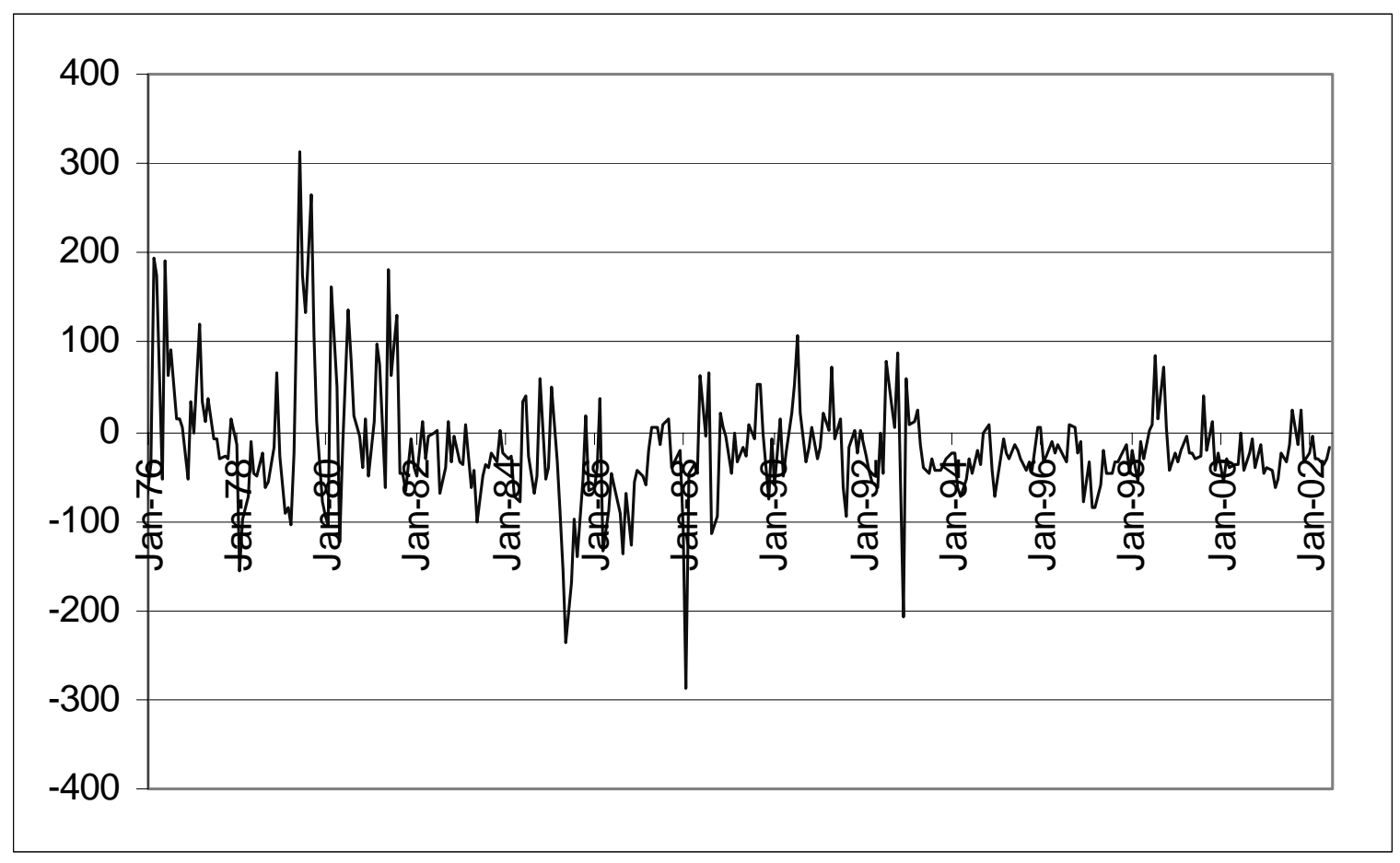

Figure 5: Conditional covariance of FOREX return and consumption growth 


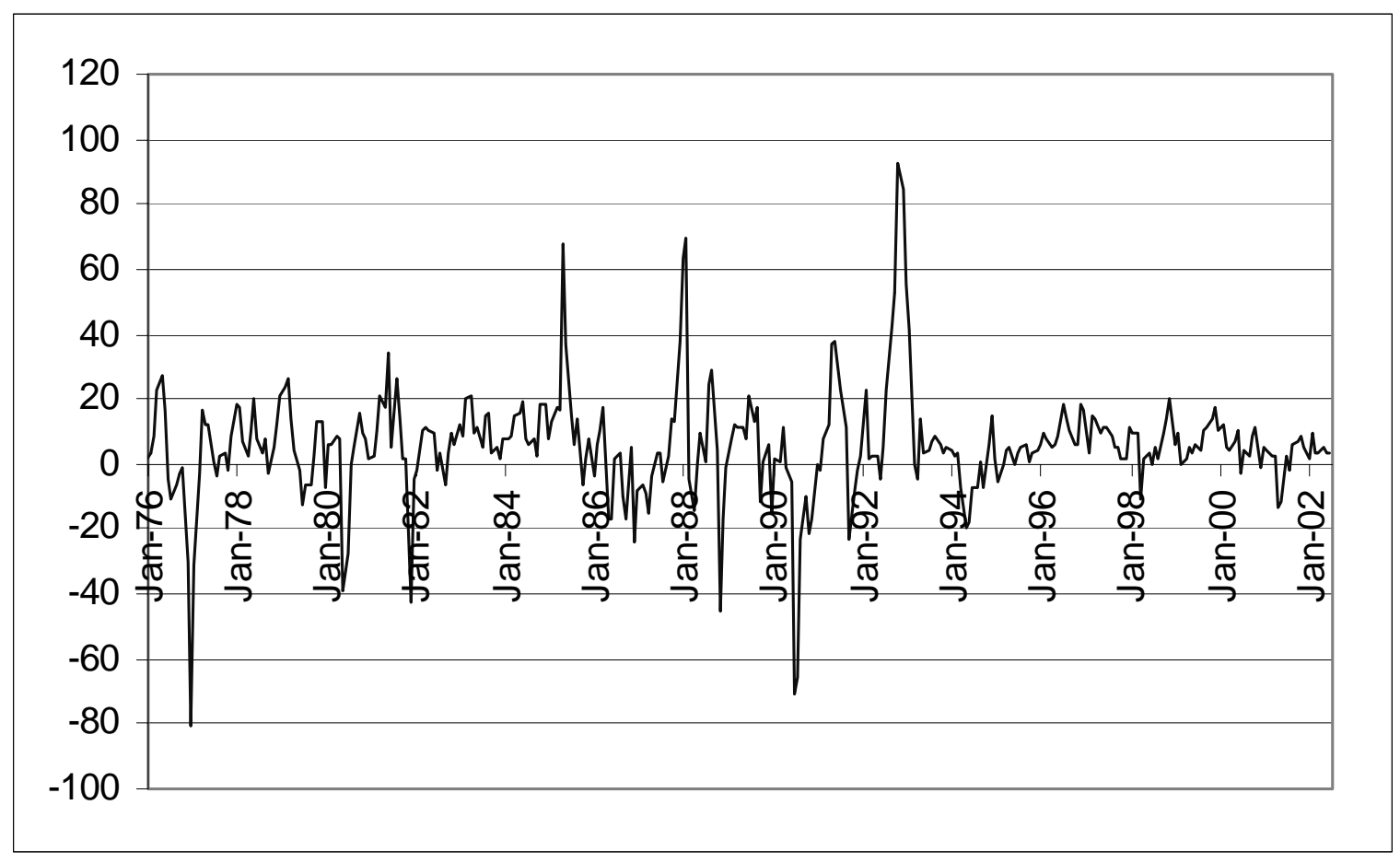

Figure 6: Conditional covariance between forex return and inflation 


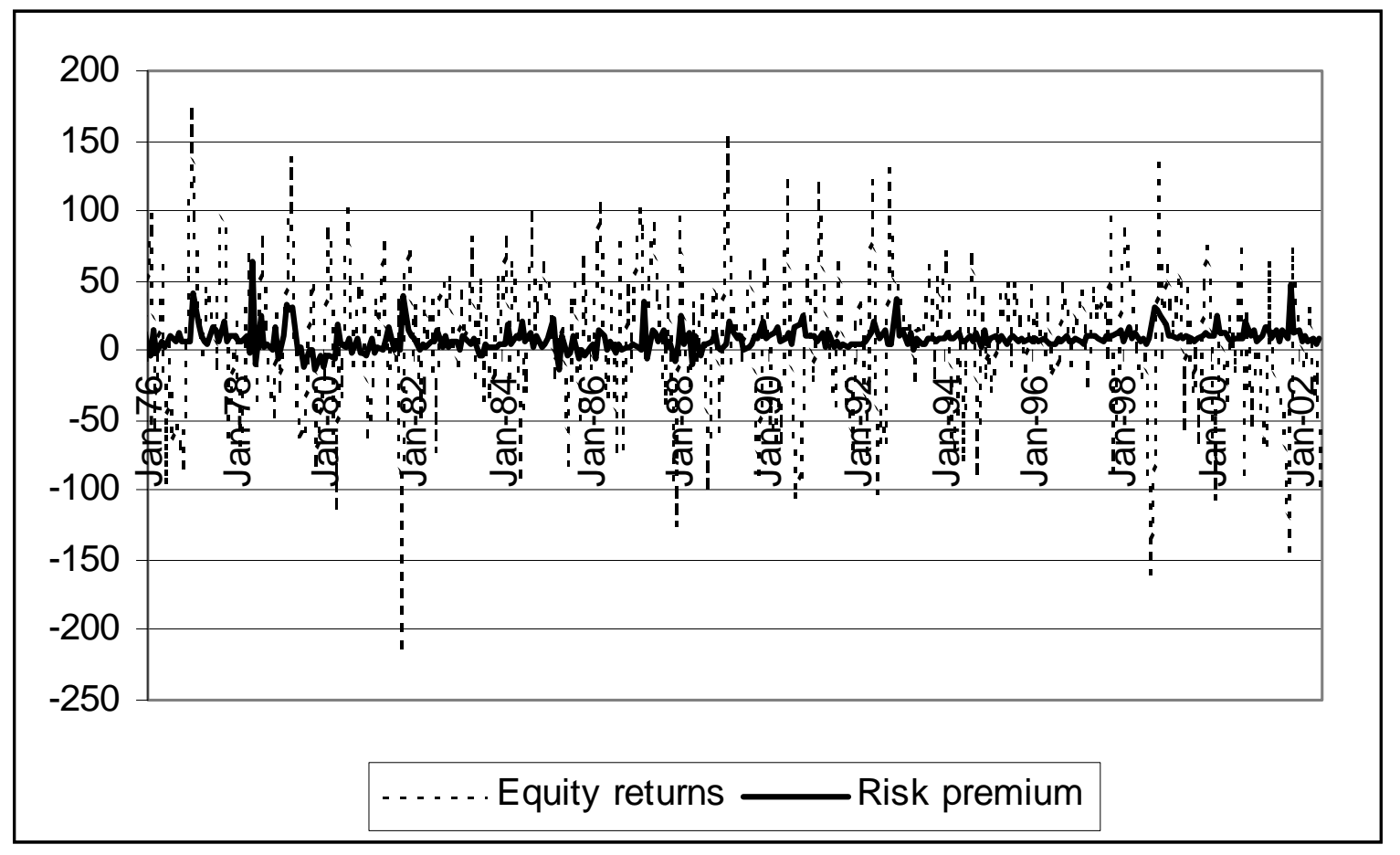

Figure 7: Equity return and risk premium for model 5 


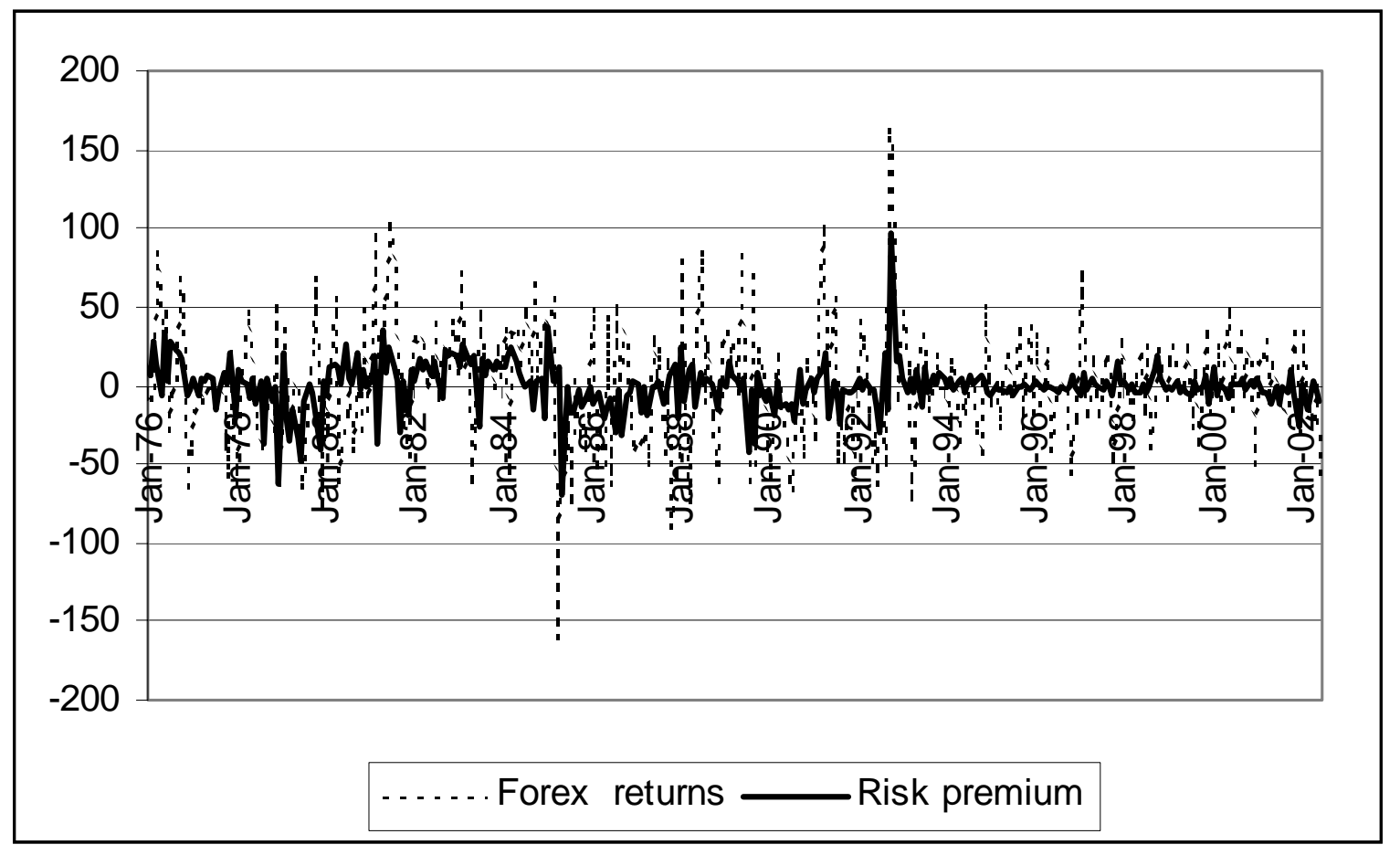

Figure 8: Forex returns and risk premium for model 5 